\title{
Very Early Post-Operative Ureteral Stent Removal in Pediatric Kidney Transplantation
}

\author{
Megan Adams*, Michael Wachs and Jens Goebel \\ Department of Transplant Surgery, University of Colorado, USA \\ *Corresponding author: Megan Adams, Department of Transplant Surgery, University of Colorado, 13123 East 16th Avenue, Aurora, USA
}

Submission: 䒸April 04, 2018; Published: 些 April 20, 2018

\section{Introduction}

The incidence of urologic complications in pediatric kidney transplantation is reported to range between 2.9\%-18\% [1-3]. These complications include urinary leaks and anastomotic strictures as well as lymphoceles in some series. Major urologic complications are significantly higher in patients who are not stented at the time of transplant [4]. While technical complications may be reduced by placing a stent, the risk of other infectious complications may be increased. It has been shown that stent placement may significantly increase the risk of BK viremia and subsequent nephropathy [5]. Additionally, the rate of urinary tract infections post-operatively may be reduced by early stent removal [6]. In most literature, early stent removal is defined as prior to Post-Operative Day (POD) 15.

\section{Challenges in the pediatric population}

Commonly after kidney transplantation, our pediatric patients need either a hemodialysis catheter, peritoneal dialysis catheter or a ureteral stent removed in the operating room, as most procedures are done with either sedation or general anesthesia. This adds cost, logistical complexity and additional anesthetic risk for each patient. We therefore wondered if it would be safe to consider very early stent removal $(<\mathrm{POD} \# 5)$ in patients who do not otherwise need to return to the operating room to have another procedure (i.e. recipients of a pre-emptive transplant or recipients whose dialysis access was removed during the transplant operation). We only considered very early stent removal in patients who had an otherwise normal bladder and were making urine pre-operatively.

\section{Our experience}

Over the last 14 months (January 2017 - February 2018) we have performed 29 pediatric kidney transplants. Of these 29 patients, 3 were felt to be good candidates for very early stent removal. These 3 recipients were over the age of 10 and had anatomically normal bladders. Two of the recipients had FSGS and one had IGA nephropathy. Two of the recipients received living donor grafts. At the time of transplant, the ureteral anastomosis was done using the Lich-Gregoir ureteroneocystostomy technique. The bladder end of the double J stent was tied to the foley catheter using a 6-0 absorbable mono filament suture. On the day of discharge when the foley catheter was removed, the attached stent came out with the foley as intended. In 2 patients this was done on POD \#3, and in 1 patient this was done on POD \#4. In all 3 patients, the stent was removed without complication via this method.

\section{Results}

In these last 29 patients we have seen BK viremia and UTI rates of $10 \%$ within the first 3 months after transplant. We have seen a leak rate of $3 \%$ and no strictures in this patient population. In the 3 patients in the very early stent removal protocol, there has been no BK virus, no UTI and no leak or stricture.

\section{Opinion}

Although this is not the first description of this technique in the literature $[7,8]$, there is not much written about it in the pediatric population. Perhaps the pediatric population is one of the most useful applications given the challenges described above. We believe that in carefully selected patients it is safe to remove the ureteral stent before POD 5. As we become more comfortable with this protocol in normal bladders we may extend it into patients who have not made a normal amount of urine pre-operatively.

\section{References}

1. Emiroğlu R, Karakayall H, Sevmiș S, Akkoç H, Bilgin N, et al. (2001) Urologic complications in 1275 consecutive renal transplantations. Transplant Proc 33(1-2): 2016-2017.

2. Rossi V, Torino G, Gerocarni Nappo S, Mele E, Innocenzi M, et al. (2016) Urological complications following kidney transplantation in pediatric age: A single-center experience. Pediatr Transplant 20(4): 485-491.

3. Englesbe M J, Lynch R J, Heidt D G, Thomas S E, Brooks M, et al. (2008) Early Urologic Complications After Pediatric Renal Transplant: A SingleCenter Experience. Transplantation 86(11): 1560-1564.

4. Wilson CH, Bhatti AA, Rix DA, Manas DM (2005) Routine intraoperative ureteric stenting for kidney transplant recipients. Cochrane Database Syst Rev 19(4).

5. Hashim F, Rehman S, Gregg J A, Dharnidharka V R (2014) Ureteral Stent Placement Increases the Risk for Developing BK Viremia after Kidney Transplantation. J Transplant 2014: 459747.

6. Thompson ER, Hosgood SA, Nicholson ML, Wilson CH (2018) Early versus late ureteric stent removal after kidney transplantation. Cochrane Database of Systematic Reviews. 
7. Morris-Stiff G, Balaji V, Lord RH (1998) Simple technique for nonoperative removal of ureteric stents after renal transplantation. Ann $\mathrm{R}$ Coll Surg Engl 80(5):370-371.
8. Sansalone CV, Maione G, Aseni P, Mangoni I, Soldano S, et al. (2005) Advantages of short-time ureteric stenting for prevention of urological complications in kidney transplantation: an 18-year experience. Transplant Proc 37(6):2511-2515 (c) (i) Creative Commons Attribution 4.0

For possible submissions Click Here

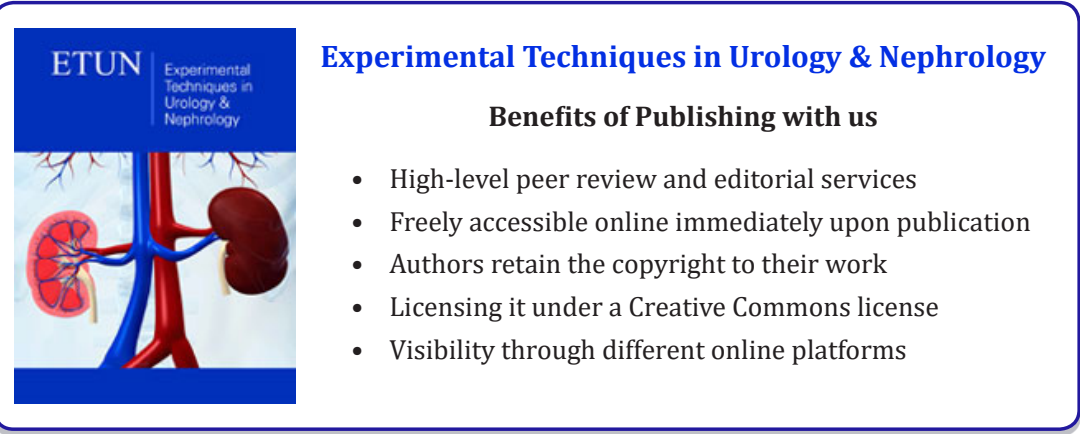

